\title{
Auricular Ossification in Adrenal Insufficiency
}

\author{
Ming-Tsang Lee ${ }^{\mathrm{a}}$, Chih-Yuan Wang ${ }^{\mathrm{a}, \mathrm{b}, \mathrm{c}}$
}

\begin{abstract}
A 50-year-old man presented with low serum ACTH level (10.4 pg/ $\mathrm{ml}$, normal 10 - 70), lower serum cortisol level $(4.5 \mu \mathrm{g} / \mathrm{dl}$, normal 5 - 25), hyponatremia (126 mmol/L, normal 135 - 153), hyperkalemia $(5.4 \mathrm{mmol} / \mathrm{L}$, normal $3.5-5.3)$ and hypereosinophilia $(13 \%$ in differential count, normal $<2 \%$ ). Physical examination revealed rigidity of ear cartilage without any signs of inflammation or scarring on the auricles. Skull X-ray demonstrated dense opacity over the auricular cartilage with normal sella turcica contour. Auricular ossification is a very rare phenomenon, and the hard, stony ear for such patients can only be moved as a single unit. Among endocrine disorders, adrenal insufficiency may be closely associated with ear ossification. We try to remind this forgotten phenomenon, ossification of auricles, for patients with adrenal insufficiency.
\end{abstract}

Keywords: Auricular ossification; Adrenal insufficiency; ACTH; Cortisol

\section{Introduction}

Auricular ossification is a rare phenomenon, and the hard, stony ear for such patients can only be moved as a single unit

Manuscript accepted for publication February 4, 2011

${ }^{a}$ Division of Endocrinology, Department of Internal Medicine, Far-Eastern Memorial Hospital, New Taipei City, Taiwan ${ }^{\mathrm{b}}$ Division of Endocrinology, Department of Internal Medicine, National Taiwan University Hospital, College of Medicine, National Taiwan University, Taipei, Taiwan

${ }^{\mathrm{c} C}$ Corresponding author: Chih-Yuan Wang, Division of Endocrinology, Department of Internal Medicine, National Taiwan University Hospital, 7, Chung-Shang South Road, Taipei, Taiwan.

Email: cyw1965@gmail.com

doi:10.4021/jem103e
[1-6]. The causes range widely, from local tissue injury to systemic disorders. Frostbite is the most commonly reported cause among local injury to ear, while adrenal insufficiency, especially Addison's disease, plays a major role in such entity [1-3]. Here we reported a 50-year-old man with adrenal insufficiency who was noted of petrified ears incidentally. The literatures for the possible etiologies were reviewed.

\section{Case Report}

This 50-year-old gentleman suffered from progressive shortness of breath with generalized anasarca in recent one month, and was admitted under the impression of congestive heart failure, NYHA functional class II. He was controlled with digoxin and diuretics.

After admission, laboratory investigations were carried out. The data showed hyponatremia $(126 \mathrm{mmol} / \mathrm{L}$, normal 135 - 153), hyperkalemia (5.4 mmol/L, normal 3.5 - 5.3) and hypereosinophilia $(13 \%$ in differential count, normal $<2 \%)$. Adrenal insufficiency was suspected. Physical examination further revealed rigidity of ear cartilage without any signs of inflammation or scarring on the auricles (Fig. 1A). The auricle of both ears only could be moved forward as a single unit.

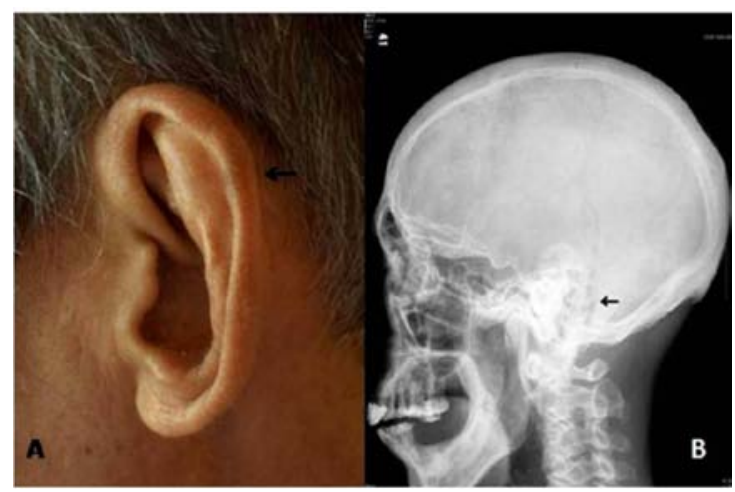

Figure 1. (A) Rigidity of ear cartilage without any signs of inflammation or scarring on the auricle (arrow). (B) Skull X-ray showing ossified auricle (arrow). 
Further laboratory data for adrenal profiles showed low serum ACTH level (10.4 pg/ml, normal 10 - 70) and lower serum cortisol level $(4.5 \mu \mathrm{g} / \mathrm{dl}$, normal 5 - 25) at 8 am. Skull X-ray (Fig. 1B) demonstrated hyperdense opacity over the auricular cartilage with normal sella turcica contour. Pituitary MRI showed normal anterior and posterior pituitary gland.

After initial consultation, the patient was treated with intravenous hydrocortisone $50 \mathrm{mg}$ every 12 hours as initial dose which was tapered gradually to cortisone acetate $25 \mathrm{mg}$ twice daily in two weeks. Two weeks later, normal serum sodium (137 $\mathrm{mmol} / \mathrm{L})$ and potassium $(5 \mathrm{mmol} / \mathrm{L})$ levels, together with normal eosinophil count $(2.1 \%$ in differential count) were detected. On the other hand, heart failure was successfully controlled after adjustment of medication, which was closely related to the electrolyte balance. But the hard and ossified ears remained without any change.

\section{Discussion}

Cartilage is an important tissue of human body without prominent vascularization, which is composed of chondrocytes and extracellular matrix. Three different kinds of cartilage are distinguished on the basis of the matrix including hyaline cartilage, fibrous cartilage and elastic cartilage.

Generally, pathologic calcification implies abnormal deposition of calcium salts, together with smaller amounts of iron, magnesium, and other mineral salts. There are two kinds of pathologic calcification. One is known as dystrophic calcification resulting from deposition of the salts in damaged tissue. The other is metastatic calcification, which may occur in normal tissues whenever there is hypercalcemia [1].

The first case of auricular calcification in a male cadaver was reported in 1866 [3]. However, fewer cases of ossified auricles have been recorded from then on. The causes varied from local tissue trauma to systemic diseases, and the most commonly reported cases were frostbite and mechanical trauma [4]. Among endocrine disorders, adrenal insufficiency may be closely associated with ear ossification [5].

For our patient, the typical signs and laboratory findings of adrenal insufficiency, including hypereosinophila, hyponatremia, and hyperkalemia, were disclosed incidentally. However, the exact cause of adrenal insufficiency for this patient was unknown. Prior report revealed that the possible etiology of ossified auricles in adrenal insufficiency might be related to long-term steroid replacement therapy [2], but for this patient, he had never received steroid, during the course of developing ossified auricles.

On the other hand, Siebenmann suggested that chronically increased ACTH secretion might be an etiological factor [7]. Barkan also reported a case of hypopituitarism with auricle ossification [8], and proposed that the ossification was due to deficiency of endogenous cortisol. Cohen explained the pathogenesis to be the result of proliferation of mesenchymal cells, which are driven to form a calcified tissue due to the coexistence of enhanced input of calcium into the extracellular space because of cortisol insufficiency [9].

Although certain mechanisms of ossification were proposed as adrenal insufficiency and long-term steroid replacement therapy, the real pathophysiology of auricular ossification was still left to be determined. We try to remind this forgotten phenomenon, ossification of auricles, for patients with adrenal insufficiency, hyperthyroidism, or rheumatic heart disease.

\section{References}

1. Gordon DL. Calcification of Auricular Cartilage. Arch Intern Med 1964;113:23-27.

2. Novick WH. Calcification of auricular cartilage in Addison's disease. Arch Otolaryngol 1960;72:448-449.

3. Bochdalek. Physiologische Verknocherung der Aurecula. Prag Vierteljahrschr 1866;89:33-46.

4. DiBartolomeo JR. The petrified auricle: comments on ossification, calcification and exostoses of the external ear. Laryngoscope 1985;95(5):566-576.

5. Wang CY, Chang TC, Chen FW. Ossification of the auricles: a forgotten sign in adrenal insufficiency. J Otolaryngol 2002;31(1):52-54.

6. Manni JJ, Berenos-Riley LC. Ossification of the external ear: a case report and review of the literature. Eur Arch Otorhinolaryngol 2005;262(12):961-964.

7. Siebenmann RE. [The ossification of the ear cartilage in Addison's disease]. Schweiz Med Wochenschr 1977;107(14):468-474.

8. Barkan A, Glantz I. Calcification of auricular cartilages in patients with hypopituitarism. J Clin Endocrinol Metab 1982;55(2):354-357.

9. Cohen AM, Talmi YP, Floru S, Tsigelman R, Kalmanovitz M, Zohar Y, Djaldetti M. X-ray microanalysis of ossified auricles in Addison's disease. Calcif Tissue Int $1991 ; 48(2): 88-92$. 